\title{
ECONOMIA, URBANIZAÇÃO E NOVAS TERRITORIALIDADES NO DESENVOLVIMENTO DE SÃO PAULO
}

\author{
Carlos A. Brandão * \\ Cláudio Schuller Maciel * \\ Fernando Cézar de Macedo *
}

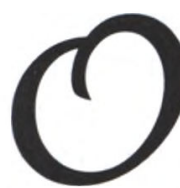

objetivo deste texto é apresentar a evolução demográfica e urbana recente no estado de São Paulo, a partir de transformações econômicas que criaram novas territorialidades, tornando a rede urbana paulista muito mais adensada e complexa $^{1}$. Encontra-se dividido em quatro partes, além desta sumária apresentação. Na primeira, são descritos aspectos do crescimento demográfico e urbano recente, destacando processos de desconcentração demográfica, seja no sentido metrópole-interior, seja pela própria periferização das metrópoles estaduais (São Paulo, Santos e Campinas). Na segunda, discute-se a interiorização do desenvolvimento paulista; na terceira, as mudanças na distribuição espacial da indústria que impactaram a rede urbana estadual. Por fim, uma breve nota sobre a evolução recente da agropecuária que também promoveu um avanço na urbanização do interior.

\section{ALGUNS ASPECTOS DO CRESCIMENTO URBANO E DEMOGRÁFICO NO ESTADO DE SÃo PAULO}

A população do Estado de São Paulo, em 2000 , representava $21,8 \%$ do total da brasileira. Estado mais populoso e segundo mais povoado do país ${ }^{2}$, sua taxa de crescimento entre $1991 \mathrm{e}$ 2000 foi de $1,8 \%$ a.a., superior à média nacional (1,6\% a.a.). Ambas ficaram, no entanto, abaixo das verificadas no período 1980-1991, que foram de, respectivamente, $2,1 \%$ e $1,9 \%$. A PNAD aponta população de quase 40 milhões, em 2004, com 48,0\% dela residindo na Região Metropolitana de São Paulo (RMSP) e a restante distribuída entre os 606 municípios do interior. Daquele total, $94,5 \%$ residiam no meio urbano, taxa que é ligeiramente superior na RMSP $(96,2 \%)$ e ligeiramente inferior no interior do estado $(92,9 \%)$.

A exemplo de tendências verificadas para o Brasil, observam-se modificações importantes no padrão demográfico de São Paulo, como envelhecimento da população, queda nas taxas de fecundidade, aumento na esperança de vida, redução nos ritmos de crescimento populacional e de urbanização e aumento das migrações de retorno. As migrações interestaduais, ainda que menos intensas, se mantiveram elevadas ${ }^{3}$ e são acompanhadas pelo aumento das intra-estaduais (incluindo as intra-metropolitanas), com o interior exercendo maior atratividade sobre os emigrantes, tanto os oriundos da RMSP quanto os de outras unidades federativas.

Embora tenha arrefecido seu crescimento, resultado da transição demográfica verificada no país a partir de fins dos anos sessenta, as taxas de incremento populacional paulista continuam acima da maioria dos demais estados, superadas apenas pelos que ainda apresentam fronteiras agrícola e mineral em expansão, como os do Norte e do Centro-Oeste, ou com taxas de crescimento econômico acima da média nacional.

Isso demonstra que apesar de se consolidarem novas áreas de atração populacional, como as duas regiões citadas, cujos estados apresentaram as maiores taxas de crescimento demográfico entre 1991 e 2000 , ou apesar da drástica redução dos ritmos das perdas de Minas Gerais que passou a reter parte significativa de seus habitantes que antes emigravam, São Paulo - principalmente seu interior continua exercendo forte poder de atração, sendo o mais importante destino para os emigrantes brasileiros, especialmente os do Nordeste.

Do ponto de vista espacial, observa-se crescimento maior dos municípios do interior, que entre 1991 e 2000 apresentaram taxa anual média de incremento populacional de $1,92 \%$ con- 
tra $1,64 \%$ da RMSP. Com isso, tem continuidade a desconcentração populacional no sentido metrópole-interior, que se inicia a partir de 1980 quando, pela primeira vez, o ritmo de crescimento populacional da RMSP é menor que a média do estado, com observância de saldos migratórios intraestaduais negativos para a primeira.

Essa interiorização contribuiu decisivamente para redefinir a posição das cidades na hierarquia urbana, pelo aparecimento de novas funções geradoras de novas centralidades, o que torna a rede urbana paulista muito mais complexa e densa. Em geral, observase que o crescimento das cidades médias esteve vinculado, como se destaca adiante, ao processo de desconcentração do desenvolvimento paulista, especialmente o industrial, a partir dos anos 1970. Desde então, consolidam-se novos espaços urbanoregionais no estado, fortalecendo e especializando as funções de algumas aglomerações urbanas do interior, que ampliaram sua centralidade na rede de cidades estadual. Contribuiu igualmente para essa urbanização do interior do estado, o avanço da agropecuária paulista, especialmente na última década do século XX.

Ressalta-se, no entanto, que o interior do estado não deve ser visto como um recorte regional único, pois essa simples agregação esconderia o fato de que a interiorização (econômica e populacional) foi muito mais intensa em alguns municípios, ainda que todas as regiões do estado tenham se beneficiado dela. Como exemplo do caráter relativamente concentrado dessa desconcentração demográfica, cabe lembrar que somente a RA de Campinas respondia por $28,2 \%$ do total de residentes no interior. Para se ter idéia de seu peso, basta mencionar que Sorocaba, a segunda mais populosa, eqüivalia a menos da metade desta. Ademais, as regiões apresentam estru- turas produtivas distintas que ficam encobertas pela agregação do interior em um único recorte territorial.

Portanto, apesar da interiorização, a população paulista manteve-se relativamente concentrada nas duas maiores Regiões Administrativas (RA), a RMSP e a de Campinas, que totalizam $62,9 \%$ dos residentes no estado em 2000, a mesma participação de 1991 e um pouco abaixo da de 1980 (63,1\%). Em boa medida, parte da perda de participação relativa da metrópole foi apropriada pelo crescimento da RA de Campinas, especialmente por seu município sede, demonstrando o caráter relativamente limitado dessa desconcentração demográfica no sentido do interior mais longínquo.

Se a RMSP apresenta ritmo de crescimento populacional mais reduzido que a média estadual entre 1991 e 2000 , o crescimento da capital foi ainda menor $(0,9 \%)$, contrapondo-se à média dos demais municípios metropolitanos que foi de $2,8 \%$, ratificando o movimento espacial de periferização que vem, desde os anos sessenta, acompanhado por forte segregação que marca principalmente as cidades brasileiras de grande porte, em especial as metrópoles.

Nelas, as populações pobres são forçadas a movimentos sucessivos de invasão de espaços vazios distantes do centro urbano principal, muitas vezes fora do perímetro urbano, não raro em áreas próximas a mananciais e reservas ecológicas. Há que se registrar que, paradoxalmente, a população rural da RMSP foi acrescida em mais de 400 mil pessoas entre 1991 e 2000 , provavelmente refletindo esse duplo processo de periferização/segregação que move a população de baixa renda para pontos longínquos do centro urbano em áreas, mormente, sem infra-estrutura necessária para atender as demandas da população.

Por outro lado, há também uma "periferização" da população de alta renda, que, fugindo da violência e da deterioração urbana que aumentaram ainda mais na década de noventa, procura segurança em condomínios fechados, em áreas distantes do core metropolitano que ofereçam amenidades físicas e sociais, com boa infra-estrutura e fácil acesso a eixos viários. Ambas periferizações geram movimento extensivo e predatório que vem moldando a configuração territorial das cidades brasileiras, sendo visíveis, também, nas duas outras metrópoles estaduais: a de Campinas e a da Baixada Santista.

Os problemas tipicamente metropolitanos, que se manifestam mais fortemente na RMSP, criam externalidades negativas (encarecimento dos terrenos, legislação ambiental mais rígida, encarecimento da mão-de-obra...), que "empurram" parte da atividade produtiva para fora da metrópole em direção a áreas do interior dotadas de boa infra-estrutura, especialmente acesso aos eixos de transporte, que se apropriaram da desconcentração metropolitana.

Isso não significa que a RMSP tenha perdido primazia e/ou que esteja passando por um processo de esvaziamento sócio-econômico; ao contrário, a rede urbana paulista complexifica-se a partir do comando da metrópole que detêm, ainda, parcela substancial (quantitativa e qualitativamente) das atividades econômicas localizadas no país. No entanto, novos pontos de dinamismo econômico surgem no interior, redesenhando suas articulações com a metrópole.

Essa interiorização das atividades é acompanhada por aumento dos fluxos migratórios intra-estaduais em direção às cidades do interior de grande e médio porte, destacando-se o fluxo de migrantes que partem da RMSP em direção as demais regiões do estado. Entre 1995 e 2000 mais de 400 mil 
pessoas emigraram da metrópole para o interior paulista, especialmente para as regiões administrativas de Campinas, Sorocaba e São José dos Campos. Da mesma forma, mais de $500 \mathrm{mil}$ emigraram da metrópole para outros estados.

Segundo Hogan et al. (2000: 66) “esta 'expulsão' da população da metrópole está, de um lado, vinculada a um retorno à $U F$ de origem e também significa que a metrópole deixou de ser, para muitos, o ponto de destino definitivo, ensejando situação de menor estabilidade ou até significando um local de passagem na redistribuição populacional do estado". Significa, também, que os territórios com maior dinamismo econômico no interior acenam com novas possibilidades para a população migrante.

Dessa forma o interior paulista tornou-se mais atrativo para os imigrantes, o que resultou em ritmo maior de crescimento populacional. No entanto, como já frisamos, esse crescimento se deu de forma muito desigual entre as 14 RAs interioranas, com particular destaque para as de Campinas, Sorocaba, São José dos Campos e Santos, cujas taxas anuais médias de crescimento, de $2,3 \%$ para as duas primeiras e $2,1 \%$ para as outras duas, foram as maiores do estado. Em contraposição, Presidente Prudente $(0,8 \%)$, Araçatuba $(1,0 \%)$ e Barretos $(1,1 \%)$ apresentaram as mais baixas.

Esse desempenho é reflexo das condições econômicas que fizeram emergir novas áreas dinâmicas localizadas fora da metrópole. Tais áreas consolidaram alguns centros regionais, dinamizando, muitas vezes, parte de seu hinterland. A rede de cidades que vai se adensando e se complexificando, apresenta tendência de seguir pelos principais eixos rodoviários estaduais que integram as principais cidades da rede urbana à RMSP, reforçando a idéia de que o município de São Paulo, a despeito de sua perda de participação demográfica e industrial no total do estado, mantém, e provavelmente intensifica, sua primazia sobre a rede urbana paulista e brasileira.

É importante, portanto, analisar a dinâmica da economia recente em São Paulo para entendermos o comportamento das diferentes regiões do estado que vem tornando a rede urbana muito mais adensada e complexa. É o que tentaremos fazer a seguir.

\section{INTERIORIZAÇÃO DO DESENVOLVIMENTO PAULISTA}

As mudanças no padrão demográfico estadual, processadas a partir da década de 1980, se refletem no maior ritmo de crescimento populacional do interior e exigem entendimentos mais precisos sobre os efeitos da dinâmica sócio-econômica paulista, com a formação e a consolidação de novas áreas dinâmicas em seu território. Com isso, redefinir-seia o desenho de sua rede urbana, segundo uma lógica de centralização e descentralização que vai estruturando uma nova hierarquia espacial no estado, com importância crescente das aglomerações urbanas do interior, sem que a RMSP perca sua centralidade no processo de acumulação, a despeito de ver reduzida sua participação relativa nas estruturas produtivas e demográficas estaduais.

É bom lembrar que a rede urbana de São Paulo foi estruturada originalmente a partir do complexo cafeeiro. Foi, contudo, a industrialização (e a decorrente criação de extensa malha viária que compõe uma infra-estrutura ímpar no país) que lhe deu maior adensamento e complexidade. Com ela, a RMSP consolidou sua influência econômica e demográfica não apenas sobre o território paulista, mas também sobre o nacional, concentrando parcela significativa do $\mathrm{VTI}^{4}$ da indústria de transformação e da população brasileiras, além dos serviços mais especializados.

Os processos de desconcentração econômica e de modernização da agropecuária a partir dos anos setenta e o baixo ritmo de crescimento da economia nacional nas duas décadas seguintes tiveram efeitos significativos sobre a RMSP, que perdeu participação na indústria de transformação brasileira. Ocorreu o surgimento de áreas economicamente dinâmicas localizadas fora da RMSP, definindo novas dimensões territoriais na produção, não apenas em São Paulo, mas também em vários espaços sub-regionais em outras unidades da federação.

Como largamente discutido ${ }^{5}$, a desconcentração industrial assumiu concomitantemente um duplo sentido, com repercussões importantes sobre a área metropolitana e sobre aglomerações urbanas de maior porte do interior do estado e em algumas cidades médias brasileiras.

Seu primeiro sentido foi o ganho de participação das demais unidades federativas, que ampliaram progressivamente seu peso na indústria brasileira em detrimento de São Paulo: 41,9\% em $1970 ; 45,6 \%$ em $1980 ; 52 \%$ em 1985 ; $54,7 \%$ em 2000 e $59 \%$ em 2003. Cidades de porte médio - normalmente capitais estaduais, com infra-estruturas capazes de atender às exigências locacionais da indústria, foram as principais beneficiárias desse movimento. Em 1970, segundo Diniz e Crocco (1996), eram 33 aglomerações industriais relevantes no país, com empregos industriais acima de 5 mil pessoas em cada uma. Em 1980 e 1990, esses números saltam para 76 e 90 , respectivamente.

O segundo sentido repercutiu mais diretamente na reconfiguração da rede urbana de São Paulo, com o aumento 
da participação do interior em sua indústria de transformação, cujo peso saltou de 25,3\% em 1970 para 43,3\% em 1985; continuando a aumentar no período seguinte: $48,1 \%$ em 1995 , $58,5 \%$ em 2000 e $61,7 \%$ em $2003^{6}$.

Ambos os sentidos da desconcentração representaram perdas de participação da RMSP nas indústrias brasileira e paulista. A contrapartida foi que o crescimento de cidades de porte médio no Brasil e no estado de São Paulo acabou por aumentar sua participação na indústria nacional, modificando o mapa da indústria brasileira ${ }^{7}$.

$\mathrm{Da}$ mesma forma, o avanço da fronteira agrícola e mineral no país reforçou o processo de desconcentração, acelerando a urbanização do CentroOeste e do Norte, fato que contribuiu para o deslocamento de parte da agroindústria para fora do estado de São Paulo. Paralelamente, a modernização da agropecuária paulista reforçaria o peso de algumas cidades de porte médio do interior, aumentando a participação do agro no PIB estadual na década de $1990^{8}$. Em 1970 esta participação era de $5,7 \%$, caindo para $3,9 \%$ em 1980 e $3,5 \%$ em 1989 . No entanto em 2003 atinge 7,7\%. A participação de São Paulo na agropecuária brasileira saltou de $18,2 \%$ em 2000 para $23,9 \%$ em $2003^{9}$. Evidentemente, este crescimento foi apropriado pelas cidades do interior, intensificando-lhes a urbanização e a maior divisão do trabalho, com surgimento de uma série de serviços diversificaram o terciário não metropolitano.

No geral, o que se observa no período pós-1970, especialmente a partir da década de oitenta, para o Brasil e para São Paulo, é um processo de desconcentração econômica que é acompanhado por um outro de desconcentração urbana e demográfica, refletida em taxas de crescimento das metrópoles abaixo das de cidades de porte médio.

Para entender melhor esse comportamento, traçamos a seguir a evolução recente da indústria e da agropecuária paulista que criaram as condições materiais para alterações no ordenamento territorial do estado.

\section{DISTRIBUIÇÃO ESPACIAL DA INDÚSTRIA PAULISTA E URBANIZAÇÃO}

A RMSP, apesar das perdas de participação, ainda respondia por $38,3 \%$ da indústria de transformação estadu$\mathrm{al}^{10}$, em 2003, apresentando a mais diversificada estrutura produtiva. Os complexos metal-mecânico e químicolpetroquímico respondiam por mais de $70 \%$ de sua indústria naquele ano. Muitos dos seus ramos detinham elevada participação estadual, tais como material de transporte (45\%) e produtos químicos (45\%).

A capital, em 1980, detinha 56,3\% da indústria metropolitana $(36,1 \%$ da estadual), mas, em 2003, sua participação cai para apenas $38,6 \%$ (14,7\% da estadual). Portanto, além do fenômeno de interiorização da indústria paulista anteriormente citado, observase transbordamento e espraiamento de atividades para municípios da periferia da RMSP e de seu entorno mais imediato, que apresentam boas condições de infra-estrutura. Plantas importantes localizam-se em Barueri, Diadema, Guarulhos, Mauá, Taboão da Serra e São Bernardo que aumentaram suas participações na indústria metropolitana entre 1980 e 2003. Como resultado desse movimento as relações sócioeconômicas entre os municípios tornaram-se muito mais complexas e articuladas.

No interior, a RA de Campinas foi a que mais ganhou no processo de desconcentração da indústria paulista. Em 2003, representa 26,3\% da indústria estadual e $43,4 \%$ da do interior. Em
1980, esses números eram respectivamente $15,1 \%$ e $42,6 \%$. Desde a década de 60 , esta RA tem a indústria mais vigorosa e expressiva do interior, abrigando modernas plantas sucroalcooleiras, alimentícias, têxteis, de papel e celulose, química, petroquímica e metal-mecânica, consolidando posição de destaque no cenário nacional. $\mathrm{O}$ valor da produção industrial da RA de Campinas é o segundo do país, superado apenas pelo da RMSP.

Beneficiada por grandes investimentos públicos federais e estaduais nas décadas de 1970 e 1980, alguns de seus segmentos industriais apresentam importância estratégica, por serem intensivos em tecnologia e conhecimento. Isso pode ser aferido a partir da estimativa de que $61,7 \%$ de sua indústria é de alta ou média alta tecnologia, contra média estadual de $55,2 \%$ e nacional de $47,5 \%$.

Portanto, uma retomada do crescimento econômico, especialmente o industrial, deverá ter impacto maior na RA, aumentando a centralidade do município de Campinas e a atratividade da região sobre a população emigrante de outras áreas do estado e do país. Entre 1995-2000 entraram na região quase 400 mil imigrantes brasileiros, sendo 224,5 mil originários de outras partes do estado de São Paulo. Embora tenham saído 179,3 mil - mais da metade para outras regiões paulistas, o saldo final mostra que sua economia tem sido importante fator de atração populacional, ainda que o crescimento econômico do período tenha sido baixo, dados os efeitos da política econômica federal sobre a economia de São Paulo.

Cabe destacar que, assim como ocorreu na metrópole paulistana, observam-se processo de desconcentração intra-regional - especialmente do município-sede de Campinas para seu entorno metropolitano - determinado, dentre outros fatores, por movimentos inerentes à lógica de lo- 
calização industrial, principalmente pela excelente oferta regional de transporte - aéreo, rodo e ferroviário - além de outros, induzidos por políticas de atração e/ou "guerra fiscal" dentro do próprio espaço regional, o que criaram oportunidades de investimentos fora do município de Campinas.

Como maior beneficiária da interiorização do desenvolvimento paulista, o espaço metropolitano de Campinas adensou sua malha industrial, aumentando sua participação na indústria regional e estadual. É importante registrar que a Região Metropolitana de Campinas (RMC) detinha $53,4 \%$ da indústria da RA em 1980, aumentando para $56,3 \%$ em 1990 e $62,2 \%$ em 2003. Dentre os principais municípios metropolitanos, destaca-se Paulínia cuja participação na indústria da RA saltou de 6,2\% em 1980 para 29,4\% em 2003. Esse desempenho é explicado pela consolidação da Refinaria do Planalto, pela expansão da produção e pelos preços favoráveis do petróleo. Outras localizações industriais como Indaiatuba e Jaguariúna, beneficiadas pela localização no espaço metropolitano, também vêm aumentando participação na indústria regional.

Outras duas RAs se destacam pela produção industrial: a de São José dos Campos e a de Sorocaba. A primeira respondia em 2003 por 10,9\% da indústria paulista. Guarda semelhanças com a região de Campinas, seja por sediar diversificado parque metal mecânico e químico-petroquímico, que responde por quase $80,0 \%$ de sua estrutura industrial em 2003, seja pela importância do pólo tecnológico, particularmente o parque aeroespacial brasileiro. Em razão disso apresenta uma estrutura industrial fortemente centrada em segmentos de alta ou média alta tecnologia (76,6\%). Espacialmente, a indústria concentra-se no municípiosede e adjacências, que responde por $67,2 \%$ do tč́al regional e Taubaté e seu entorno, aonde se localizam $17,7 \%$ da produção industrial regional.

$\mathrm{O}$ crescimento industrial da região transformou-a em área de atração populacional (recebeu mais de $125 \mathrm{mil}$ pessoas entre $1995-2000^{11}$ ). Como conseqüência, seu crescimento demográfico está levando a mudanças na ocupação intra-urbana, com aumento da periferização das maiores cidades da região, que se reflete na ocupação de áreas fora do perímetro urbano, o que poderia explicar o fato de que sua população rural voltou a crescer entre 1991 e 2000, depois de um longo período de decréscimo.

A RA de Sorocaba, por sua vez, ampliou sua participação na indústria estadual saltando de 4,0\% em 1980 para $4,9 \%$ em 1990 e $5,6 \%$ em 2003. Sua pauta produtiva é menos concentrada, embora com uma tessitura industrial que se aproxima um pouco de regiões de forte aglomeração urbana e industrial, como as metropolitanas. Destacam-se produtos alimentícios ( $17 \%$ do VAF regional em 2003), minerais não metálicos $(8,3 \%)$, material de transporte (cerca de $10 \%$ ), produtos químicos (cerca de 10\%), e máquinas e equipamentos $(7,4 \%)$ que lhes compõem os principais segmentos.

Embora outras regiões do estado tenham apresentado melhor desempenho industrial, a RA de Sorocaba apresentou dinamismo suficiente para tornar-se, depois da de Campinas, a principal área de atração populacional do interior, entre 1995 e 2000 . Recebeu no período 163,5 mil imigrantes, sendo 111,3 mil de outras regiões de São Paulo. Apesar de emigrarem dela 80,6 mil para outras RAs paulistas ou outros estados brasileiros, a RA demonstrou dinamismo econômico para tornar-se área de atração populacional. Esse crescimento populacional possibilitou diversificação do comércio e dos serviços na região centralizada em Sorocaba. Embora esta sofra concor- rência pela proximidade e facilidade de locomoção da população para a RMSP, o crescimento de seu terciário ampliou-lhe a centralidade.

Em relação às RAs do centro, norte e oeste do Estado, suas estruturas produtivas mostram forte presença agroindustrial, com alta participação do beneficiamento ou transformação de produtos alimentares, bebidas e álcool de cana-de-açúcar. O somatório dessas três atividades perfez, no ano de 2003, percentuais largamente predominantes do VAF regional em Barretos (92\%), Presidente Prudente (80\%), Araçatuba (74\%), São José do Rio Preto $(70 \%)$, Marília (68\%), Bauru (66\%), Ribeirão Preto $(61 \%)$ e Franca (59\%). Na RA Central repete-se o alto peso de produtos alimentícios/ bebidas (cerca de 55,5\%), com volume expressivo de beneficiamento de frutas cítricas. Como atividades complementares à agroindústria, também se desenvolveram em algumas dessas RAs, importantes segmentos de máquinas agrícolas e fertilizantes. Máquinas e equipamentos e outros setores do complexo metal-mecânico ligados à agropecuária.

A expansão da agropecuária merece alguns comentários, ainda que sucintos, pelo papel que vem desempenhando nos municípios dessas regiões, com impactos importantes sobre suas redes urbanas.

\section{AGROPECUÁRIA E URBANIZAÇÃO PAULISTA}

Conforme já destacado, a agropecuária paulista vem passando por expansão, em bases modernas e competitivas, impulsionada pelo aprofundamento do capital financeiro que estimula o setor a partir de uma lógica internacional de financiamento e pela incorporação de inovações tecnológicas.

Essas inovações, no entanto, como 
lembra Gonçalves (2006), aumentaram as práticas mecanizadas, incluindo a colheita, reduzindo desta forma não apenas a demanda por bóias-frias como o nível de emprego, não obstante se observar um crescimento do assalariamento formal a partir de 1985 . O caso da cana-de-açúcar, que teve expressivo crescimento em praticamente todas as RAs do interior, é típico. Apesar do aumento da área plantada e da produção nos anos noventa, sua forte mecanização foi acompanhada por processo de aumento do desemprego, pela redução do trabalho temporário, ainda que a formalização tenha aumentado, como descreveu Gonçalves (2006).

Esse movimento de expansão da agropecuária e da agroindústria, por razões espaciais óbvias, vai beneficiar mais diretamente os municípios do interior, gerando um duplo impacto sobre sua rede urbana. Primeiro, o aumento do desemprego pela incorporação crescente de técnicas intensivas em capital, aliado a uma conjuntura econômica nacional desfavorável. Esse movimento de desestruturação do mercado de trabalho generaliza, para as cidades médias, que vêm apresentando crescimento demográfico acima das metrópoles - como destacamos anteriormente, problemas que eram tipicamente metropolitanos ou de cidades grandes.

Com isso, o processo de interiorização do desenvolvimento foi também um processo de interiorização dos problemas urbanos, agravados por uma conjuntura na qual o investimento público tem se mostrado absolutamente insuficiente para fazer frente a questões substantivas que passaram a fazer parte do cotidiano dessas cidades.

Por outro lado, a expansão da renda agropecuária gera estímulos para a diversificação da oferta de serviços e para o comércio, aumentando a centralidade dos municípios de porte médio, principalmente daqueles que são capitais regionais - Ribeirão Preto, Araçatuba, Barretos, São José do Rio Preto, Araraquara, Marília... -, aumentando a centralidade delas sobre suas hinterlands. Com isso, a rede urbana paulista torna-se mais complexa e adensada.

\section{* Carlos A. Brandão, Cláudio Schuller Maciel e Fernando Cézar de Macedo são Professores do IE/ UNICAMP e Pesquisadores do Centro de Estudos do Desenvolvimento Eco- nômico (CEDE).}

\section{NOTAS}

1 - Este trabalho está baseado nos capítulos sobre demografia, urbanização e indústria escrito pelos autores na pesquisa ISSP/CEDE-IE-UNICAMP. Ver Cano et. alli (2006).

2 - O primeiro é o Rio de Janeiro, com densidade de demográfica de $329,3 \mathrm{hab} /$ $\mathrm{km}^{2}$. Destaca-se também o Distrito Federal, com 353,5 hab/. $\mathrm{km}^{2}$.

3 - A maioria dos pesquisadores vem considerando uma queda no ritmo das migrações interestaduais recentemente, tomando por base a informação referente à data-fixa, ou seja, qual o lugar de residência anterior há exatamente cinco anos antes da data de referência da pesquisa. Observa-se com base nela que as entradas em São Paulo entre 1995-2000 foram $12,1 \%$ menores do que no período 1986-1991, enquanto as saídas foram significativamente maiores $(36,4 \%)$.

4 - Valor de Transformação Industrial.

5 - Ver Cano (1988), Cano (1992) e Negri (1996).

6 - Para 1970, 1980 e 1985, censo industrial, com base em Cano (1998). Para os demais anos, estimativa com base no VAF.

7 - Ver Diniz e Crocco (1996).

8 - Deve-se registrar que o aumento do peso da agropecuária decorre não apenas desse acelerado processo de modernização, mas também dos efeitos da crise na economia brasileira, que repercutiram mais intensamente sobre a indústria paulista, contribuindo para sua queda no PIB estadual.

9 - Participação no valor agregado da agropecuária, segundo informações do documento Contas Regionais 2003 do IBGE.
10 - A análise da indústria de transformação está baseada nos dados do Valor Adicionado Fiscal (VAF), informados pela Secretaria da Fazenda do estado de São Paulo.

11 - Embora 64,5 mil tenha emigrado para outras regiões de São Paulo ou outras UFs. De qualquer forma, o saldo positivo indica que essa foi, de fato, uma área de atração populacional no período.

\section{REFERÊNCIAS BIBLIOGRÁFICAS}

CANO, W. (coord.)

(1988) O processo de interiorização da indústria paulista - 1920 a 1980. São Paulo, Fundação SEADE. (Coleção Economia Paulista).

CANO, W. (coord.) (1992) São Paulo no limiar do século $X X I$. São Paulo, Fundação SeadeSEPLAN.

CANO, W.

(1998). Desequilíbrios Regionais e Concentração Industrial no Brasil: 1930:1995. Campinas: UNICAMP/IE, $2^{\mathrm{a}}$ ed.

CANO, W.; BRANDÃO, Carlos A.; MACEDO, Fernando Cézar de; MACIEL, Cláudio S. (Coords.)

(2006) A economia paulista: principais transformações entre 1980 e 2003. Campinas: ISPP/CEDE-IE-UNICAMP, 2 vol. (No prelo).

DINIZ, Clélio Campolina; CROCCO, Marco Aurélio

(1996) "Reestruturação econômica e impacto regional: o novo mapa da indústria brasileira". Revista Nova Economia, Vol. 6, № 1, p. 77-103.

FUNDAÇÃO IBGE. Contas Regionais 2003.

GONÇALVES, Sidnei; et. Alli

(2006) "Agropecuária paulista: transformações do período 1969-1971 a 2002-2004". IN: CANO, Wilson; BRANDÃO, Carlos A.; MACEDO, Fernando Cézar de; MACIEL, Cláudio S. (Coords.). A economia paulista: principais transformações entre 1980 e 2003. Campinas: ISPP/CEDE-IEUNICAMP, 2 vol. (No prelo).

HOOGAN, Daniel (org.)

(2000) Migração e meio ambiente nas aglomeraçôes urbanas. Campinas: NEPO-UNICAMP.

NEGRI, Barjas

(1996) Concentração e desconcentração industrial em São Paulo (18801990). Campinas: Ed. da UNICAMP. 